\title{
Modification in extra cellular polymeric substances of staphylococcus aureus using sesbania grandiflora
}

\begin{abstract}
Biofilm is the protective shield of microorganism which provides an enclosed environment for the bacteria to multiply and the biofilm composed of various components collectively called extracellular polymeric substance (EPS). This work concentrated on the bases of breaking the protective shield of bacteria and to study its composition and modification occurred during inhibition of bacterial EPS. The inhibition of bacterial barrier takes place due to implement of herbal extract of various concentration. Hence the Sesbania grandiflora is selected against pathogenic Staphylococcus aureus. The modification occurred on EPS of control and treated was spectroscopically analyzed (UV -Vis spectrometry, FTIR, DLS). Quantification of EPS particularly protein and carbohydrate were calculated. The efficacy of the herbal extract Sesbania grandiflora and its inhibition against the pathogenic strain of Staphylococcus aureus wereevaluated.
\end{abstract}

Volume 6 Issue I - 2017

\author{
Gandhi AD,Vizhi DK, Lavanya K, \\ Babujanarthanam R \\ Department of Biotechnology, Thiruvalluvar University, India
}

\begin{abstract}
Correspondence: Ranganathan Babujanarthanam, Department of Biotechnology, Thiruvalluvar University, Serkkadu, Vellore-632-I I5, India, Tel 9|4|62274747, Fax 9|4I62274748 Email babukmg@gmail.com
\end{abstract}

Received: August 06, 2017 | Published: August II, 2017

Keywords: Sesbania grandiflora, Extra polymorphic substances, Staphylococcus aureus

Abbreviations:FTIR,

Fourier Transform Infrared Spectroscopy; DLS, Dynamic Light Scattering; EPS, Extra Cellular Polymeric Substance

\section{Introduction}

Microorganism secret high molecular weight compound called as extra cellular polymeric substance (EPS) which is attached on the outer surface of the bacteria which is mostly release during its log phase. Bacterial EPS have been identified as one of the major components in biofilms. ${ }^{1}$ Biofilms are formed with interaction among microbial aggregates, filamentous bacterial strains, organic and inorganic particles, which are held together by EPS. ${ }^{2}$ The biofilms are complex structure where microbial cell aggregates are embedded inside a hydrated matrix made up of extra cellular polymeric substances. EPS majorly comprised of four substance called carbohydrate, protein, lipids and environmental DNA (e DNA). This biofilm acts as a protective barrier and provides resistance against antibiotics, degrading enzymes, protozoan grazers and host immune response. ${ }^{3}$

The EPS serves many functions concerning promotion of the initial attachments of cell to solid surface, formation and maintenance of micro colony and mature biofilm structure and enhanced biofilm resistance to environment stress and disinfectants. ${ }^{3}$ The mechanisms of biofilm developments process are vastly different from species to species. Many pathogenic bacteria are become multi drug resistance due to this protective shield, but on the other part rather than synthetic drug the herbal plants plays an crucial role against pathogenic bacteria. Traditionally, humans have utilized crude extracts of medicinal plants as curative agents for various ailments. Predominantly, medicinal plants were used as best substitute in treatment of different infectious diseases caused by antibiotic- resistant microbes. In view of the fact that medicinal plant and their substances have the potential to inhibit the magnification of pathogens. Apart from this, herbal medicines have received much attention as sources of lead compounds and it is environment amicable. ${ }^{4-6}$

In this work, the effect Sesbania grandiflora possessing antibiofilm activity was evaluated against the secreted EPS of Staphylococcus aureus. It is a Gram positive bacterium belonging to the family Staphylococcaceae which typically forms biofilms of clinical and industrial concern Staphyloccous aureus produce cell bound and secreted EPS where in secreted EPS initiates the attachment of planktonic cells to solid substratum thereby facilitating biofilm mode of life cycle. Sesbania grandiflora belongs to the family of Fabaceae. It is one of the traditional medicinal plants in India. The plant leaves containing natural antioxidant activity and it is used to treat several diseases. $^{7}$ Antibiofilm efficiency of pathogenic bacterium S. aureus, were investigated by emulsifying activity, quantification of protein and carbohydrate in EPS components and also it is characterized by some spectroscopic methods. Hence, the modulatory effect of Sesbania grandiflora on Staphyloccous aureus secreted EPS was investigated using spectroscopic method which shows the structural modifications due to increase in plant extract concentration.

\section{Materials and methods}

\section{Materials}

The plant leaves Sesbania grandiflora (Figure 1) were collected from rural area of Vellore district, Tamil Nadu. India. All the chemicals used in this study were analytical grade purchased from Hi media, Mumbai, India.

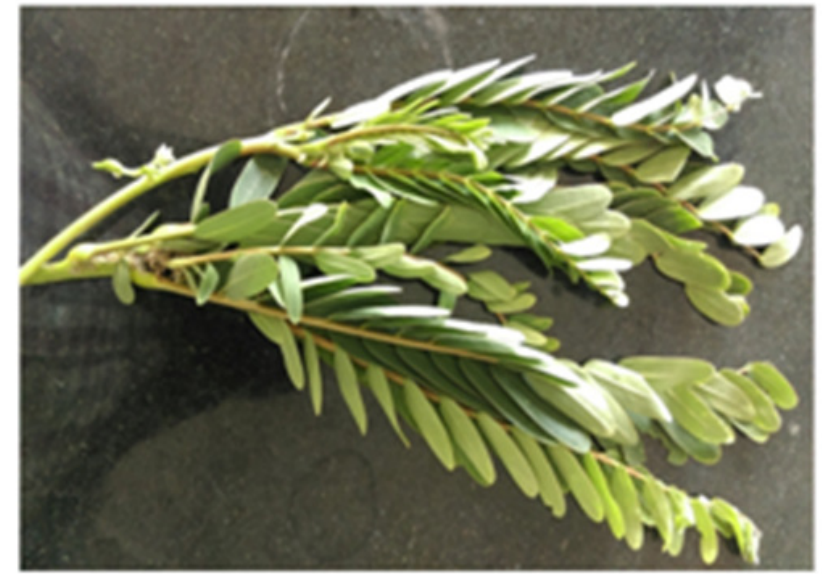

Figure I Sesbania grandiflora leaves. 


\section{Preparation of leaves extract and evaluation of antimicrobial activity}

The collected plant leaves were washed with running water and 2-3 times with distilled water. Washed leaves were shade dried at room temperature for 1 hour and weighed the plant leaves about $10 \mathrm{~g}$ grind using pestle and mortar and make into fine paste. $10 \mathrm{~g}$ of leaves paste was mixed with $100 \mathrm{ml}$ of sterile double distilled water and incubated in water bath for 2 hours at $80^{\circ} \mathrm{C}$. The extracts were filtered through whatman No.1 filter paper and the filtrate was collected and dried using hot air oven. The plant powder was used for antimicrobial activity (Figure 2).

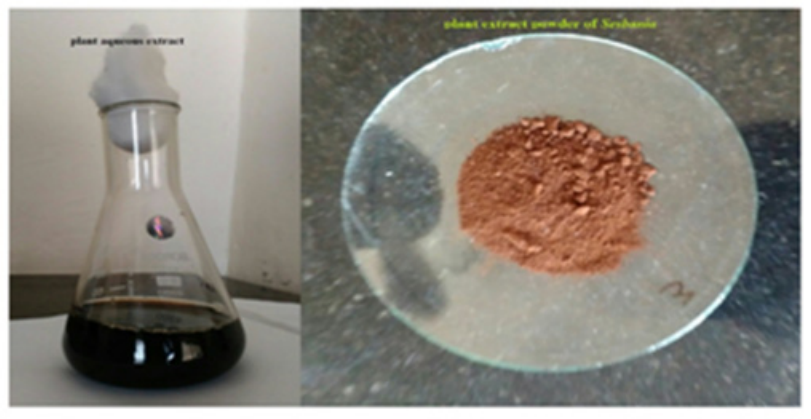

Figure 2 Sesbania grandiflora leaves aqueous extract and powder.

The antimicrobial activity of the leaves extract was determined by disc diffusion method ${ }^{8}$ against the pathogenic microorganism Staphylococcus aureus (MTCC 3160), the strain was swabbed uniformly onto the plates using sterile cotton swabs. Plates were kept in incubator at $37^{\circ} \mathrm{C}$ for 24 hours.

\section{Congo red assay for EPS}

The test microorganisms were cultured in nutrient agar plate and incubate at $37^{\circ} \mathrm{C}$ for 24 hours. The cultured plate was flooded with $0.2 \%$ congo red dye, after 15 minutes it was destained by washing twice with $1 \mathrm{M} \mathrm{NaCl}$. The congo red stain binds to the extracellular matrix such as polysaccharides and cellulose to give a dark red stained background around the colony.

\section{Extraction of EPS}

Staphylococcus aureus culture of $20 \mu 1$ (222 CFU) was added in freshly prepared $50 \mathrm{ml}$ of sterile nutrient broth and were treated with Sesbania grandiflora plant extract powder of 3 different concentration $(250,500,750 \mathrm{mg})$ and one is maintained as control without adding the plant extract then the samples were incubated at $37^{\circ} \mathrm{C}$ for 24 hours at $140 \mathrm{rpm}$. Control and the treated samples were centrifuged at $12,000 \mathrm{rpm}$ for 15 minutes at $4^{\circ} \mathrm{C}$ and to the supernatants were collected, to that three volumes of ice cold isopropanol was added and incubated overnight at $-25^{\circ} \mathrm{C} .{ }^{9}$ The incubated samples were centrifuged at 5,000 rpm for $30 \mathrm{~min}$ and pellets were collected (EPS) and air dried at room temperature. The collected EPS of control and treated were purified, and stored for further analysis. ${ }^{10}$

\section{Emulsifying activity}

The extracted control and treated EPS solution (2 mg mL-1 in deionized water) was heated at $100^{\circ} \mathrm{C}$ for $15 \mathrm{~min}$ followed by cooling $\left(25^{\circ} \mathrm{C}\right)$ and the volume was made up to $2 \mathrm{ml}$ using phosphate buffered saline (PBS). One $\mathrm{ml}$ of olive oil was added, vortex for $1 \mathrm{~min}$ and the absorbance were measured after $30 \mathrm{~min}$. at $540 \mathrm{~nm}$. The emulsifying activity was calculated in terms of percentage and the graph was plotted. ${ }^{11}$

\section{Quantification of EPS components}

Extracellular polymeric substances components were quantified by standard protocols. Total protein content was estimated by Lowry's method $^{12}$ and the carbohydrate was estimated by Anthrone method. ${ }^{13}$

\section{Percentage of EPS inhibition}

The percentage of EPS inhibition was calculated using the formula.

\section{Characterization of extracted eps}

\section{UV - Visible Spectroscopy analysis}

The control and treated EPS samples were analyzed by UV Vis spectroscopy. One mg mL-1 EPS was dissolved in Milli Q water and scanned using UV- Vis spectrophotometer (Thermo Scientific Evolution 201) from 200nm to $800 \mathrm{~nm}$.

\section{Fourier transform infrared spectroscopy}

Dried control and treated EPS samples were passing through an infrared beam and scanning the spectrum with dispersion device. The absorption areas detected and plotted as frequencies Vs intensities. The changes in functional group for the different samples were characterized by FTIR at 400-4000 cm-1 (Bruker, Tensor 27 model).

\section{Light scattering analysis}

Dynamic light scattering analysis was performed to know the stability of control and treated EPS samples using Zeta Sizer Nano ZS90 (Malven UK).

\section{Results}

In this study Sesbania grandiflora leaves extract was tested for the inhibition of extracellular polymeric substances produced by the pathogenic microorganism Staphylococcus aureus. The antimicrobial efficiency was initially determined by the agar disc- diffusion method.

\section{Evaluation of antimicrobial activity}

The Antibacterial activity of Sesbania grandiflora leaf extract powder to the bacterial strain Staphylococcus aureus shows the result at $40 \mathrm{mg}$ concentration.

\section{Congo red assay for detection of EPS}

The Congo red assay shows the present of Exo polysaccharides with the view of dark red background around the bacterial colonies (Staphylococcus aureus) which show the abundant formation of extracellular polymeric substance in overnight (Figure 3).

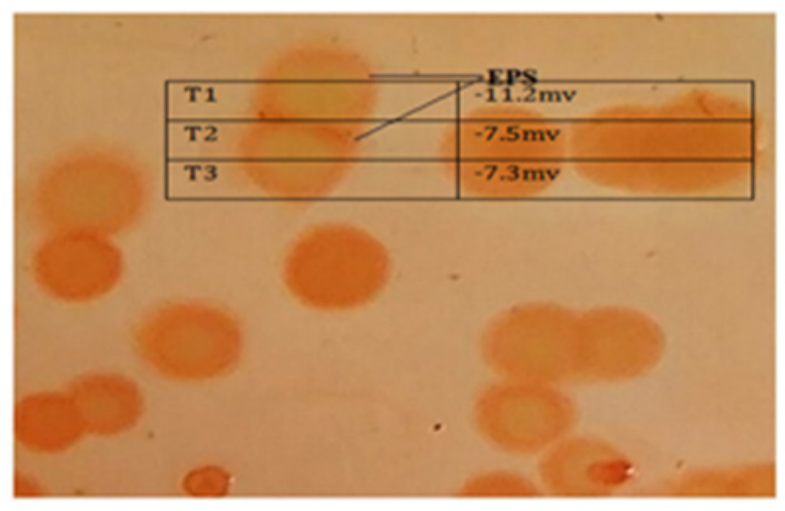

Figure 3 Congo red assay. 


\section{CFU count of Staphylococcus aureus}

The $1 \times 10^{5} \mathrm{CFU} / \mathrm{ml}$ dilution of $20 \mu 1$ bacterial suspension was swabbed on the sterile agar plate and the colonies were counted using colony counter (Figure 4).

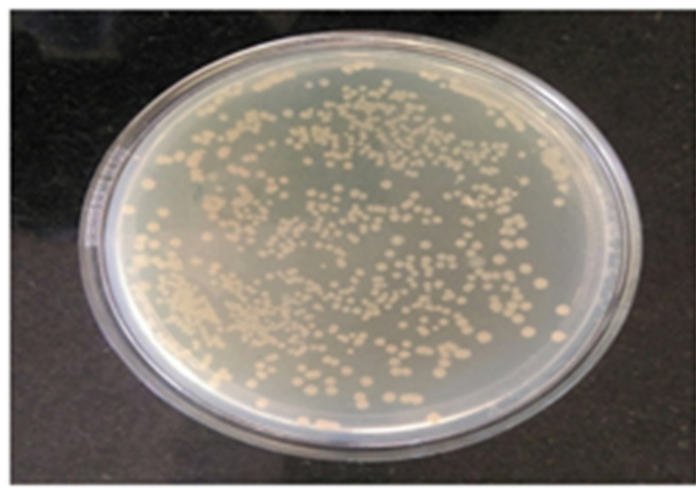

Figure 4 Spread plate of Stapylococcus aureus.

\section{Extraction of EPS}

The control and treated EPS samples was extracted, purified and dried, this samples were used for further quantifications and characterizations studies.

\section{Emulsification test}

A stable emulsion of the control and treated EPS was observed with olive oil. This yielded $48.51 \%, 53.62 \%, 72.11 \%$. This was calculated in terms of percentage of inhibition using optical density Vs intensity .The emulsifying activity of EPS was measured before $30 \mathrm{~min}$. because emulsification would break within $30 \mathrm{~min}$., due to the stability of the sample (Figure 5). The presence of both hydrophilic (hydroxyl) and hydrophobic (aliphatic $\mathrm{CH} 2$ ) functional groups may be responsible for its emulsifying property. ${ }^{14}$

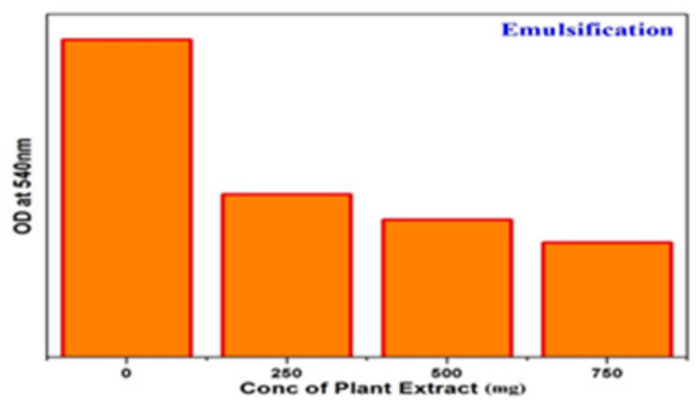

Figure 5 Histogram of Emlsification index.

\section{Quantification of EPS components}

\section{Inhibition of protein and carbohydrate levels in EPS}

The optical density of the control and treated EPS revels that the amount and inhibition percentage of the protein in the given sample by measuring at $660 \mathrm{~nm}$ (Figure 6) and inhibition percentage of carbohydrate in the given sample was measured at $620 \mathrm{~nm}$ (Figure 7). The gradual decrease in the amount of protein and carbohydrate in control and treated EPS were calculated in terms of percentage. The amount of protein in EPS decreases with the increase of plant extract. This variation in control and treated EPS is due to increase in plant extract concentration (Table $1 \& 2$ ).
Table I Comparison of protein concentration with control

\begin{tabular}{llll}
\hline S. No & $\begin{array}{l}\text { Concentration } \\
\text { of Sesbania } \\
\text { grandiflora Leaves } \\
\text { Extract }(\mathbf{m g})\end{array}$ & $\begin{array}{l}\text { Protein } \\
\text { Concentration }\end{array}$ & $\begin{array}{l}\text { Present in Control } \\
\text { and Treated EPS }(\boldsymbol{\mu g}) \\
\text { of Protein } \\
\text { Inhibition }\end{array}$ \\
\hline C & 0 & 44 & $0 \%$ \\
T1 & 250 & 41 & $2.10 \%$ \\
T2 & 500 & 37 & $6.50 \%$ \\
T3 & 750 & 31 & $14.44 \%$ \\
\hline
\end{tabular}

Table 2 Comparison of carbohydrate concentration with control

\begin{tabular}{llll}
\hline S. No & $\begin{array}{l}\text { Concentration } \\
\text { of Sesbania } \\
\text { grandiflora Leaves } \\
\text { Extract }(\mathbf{m g})\end{array}$ & $\begin{array}{l}\text { Carbohydrate } \\
\text { Concentration } \\
\text { Present in Control } \\
\text { and Treated EPS }(\boldsymbol{\mu g})\end{array}$ & $\begin{array}{l}\text { Percentage of } \\
\text { Carbohydrate } \\
\text { Inhibition }\end{array}$ \\
\hline C & 0 & 51 & $0 \%$ \\
T1 & 250 & 45 & $11.20 \%$ \\
T2 & 500 & 30 & $36.71 \%$ \\
T3 & 750 & 22 & $49.36 \%$ \\
\hline
\end{tabular}

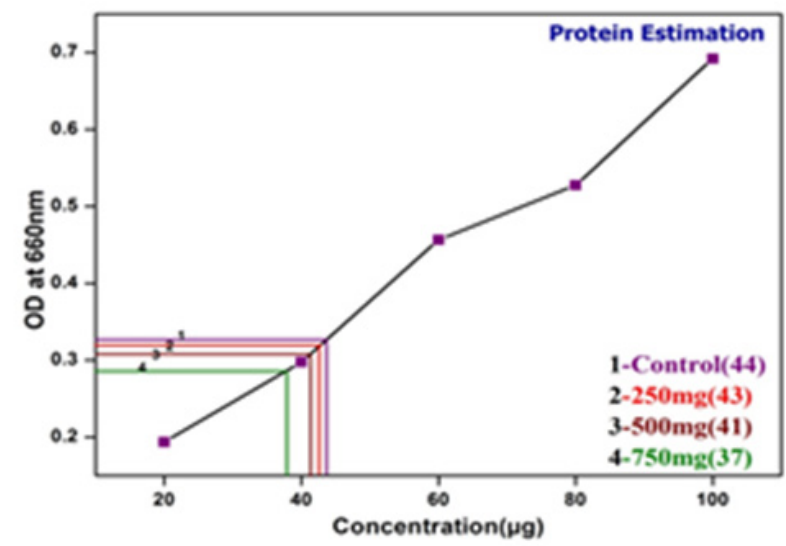

Figure 6 Estmation of Protein in EPS.

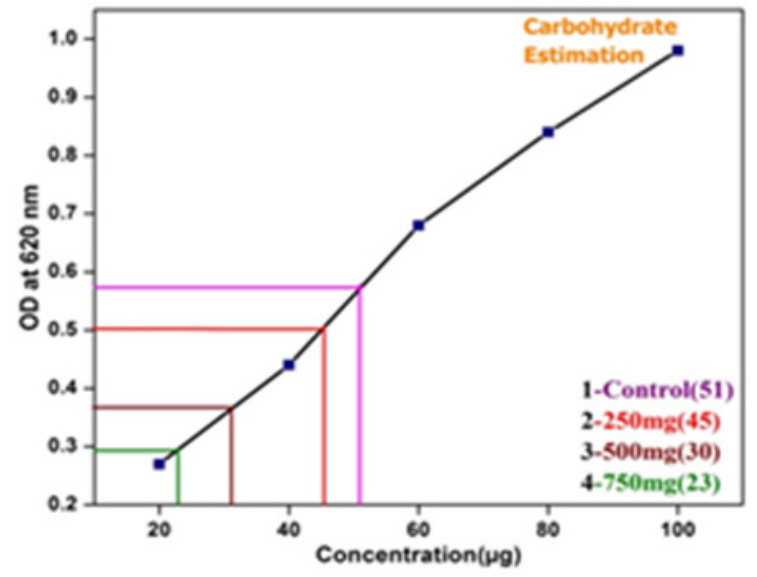

Figure 7 Carbohydrate estimation in EPS.

\section{UV visible spectrometry}

The biophysical characterization was studied using UV visible spectroscopy. UV- Vis spectroscopy analysis of control and treated EPS revealed major absorption peak at $270 \mathrm{~nm}$. A major absorption peak near 270-280nm in both control and treated samples (Figure 8). 


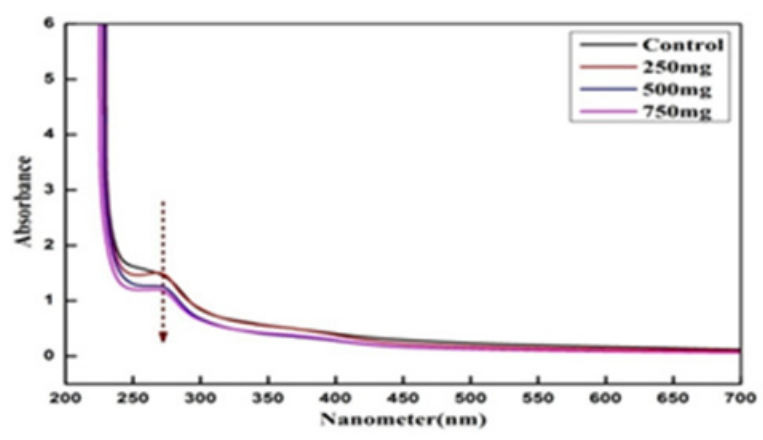

Figure 8 UV-Visible spectrum of EPS.

\section{Fourier Transform Infrared Spectroscopy (FTIR)}

Fourier Transform Infrared spectroscopy was used to find out the biomolecules. FTIR spectrum shows peak at $707 \mathrm{~cm}-1,1075 \mathrm{~cm}-1$, $1659 \mathrm{~cm}-1,2942 \mathrm{~cm}-1,3462 \mathrm{~cm}-1$ which confirms the presence of carboxylic group, O-acetyl ester linkage bond, $\mathrm{C}-\mathrm{H}$ stretching of sugar molecules, $\mathrm{C}-\mathrm{H}$ functional groups and hydroxyl group respectively (Figure 9). The gradual decrease or disappearance of peaks reveals the reduction of protein and carbohydrate content in the EPS of Staphylococcus aureus when treated with Sesbania grandiflora.

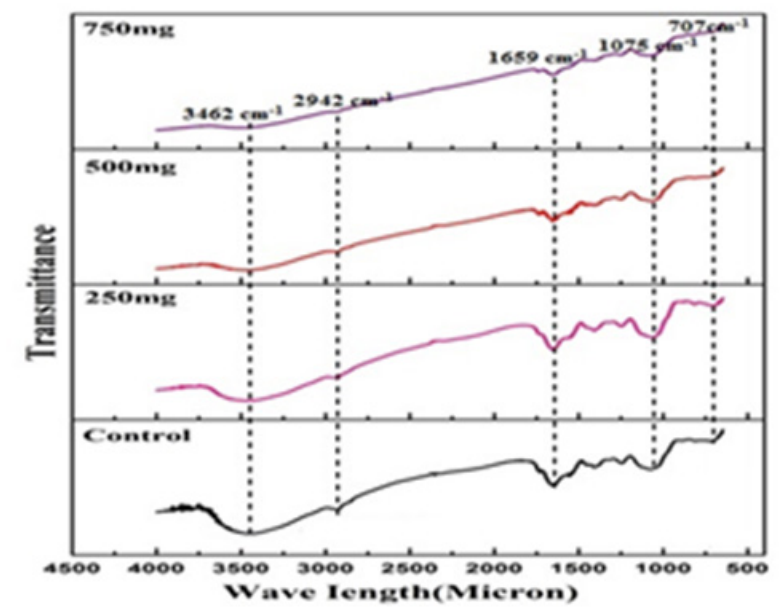

Figure 9 FTIR spectrum of EPS.

\section{Dynamic Light Scattering (DLS)}

The stability of EPS was analyzed by Zeta potential which is high in the control when compare to treated EPS (Figure 10) \& (Table 3). The value number of the zeta potential showed the stability of the EPS $^{15}$ This analysis used to check the cell wall penetration of EPS and stability of the bacteria.

Table 3 Zeta potential Peaks and its determination

\begin{tabular}{ll}
\hline EPS Samples & Stability \\
\hline C & $-12.3 \mathrm{mv}$ \\
TI & $-11.2 \mathrm{mv}$ \\
T2 & $-7.5 \mathrm{mv}$ \\
T3 & $-7.3 \mathrm{mv}$ \\
\hline
\end{tabular}
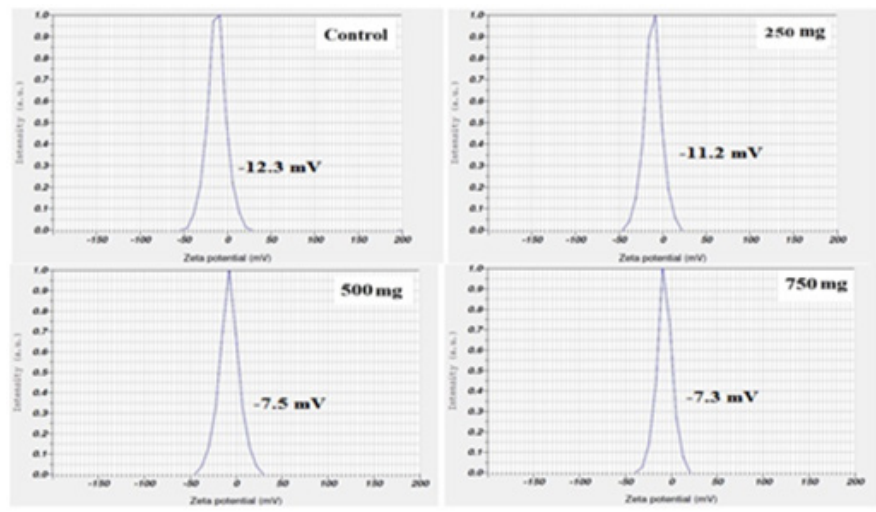

Figure 10 Dynamic Light Scattering of EPS.

\section{Discussion}

In this study, the biofilm inhibition potential of Sesbania grandiflora against Staphylococcus aureus was evaluated by using quantitative spectroscopic techniques. $40 \mu \mathrm{g}$ concentration of Sesbania grandiflora leaf extract showed potential activity against Staphylococcus aureus. Sesbania grandiflora extract have been known to contain alkaloids, flavonoids, saponins, tannins and steroids. ${ }^{16}$ These active compounds have the potential to inhibit adhesions and prevent matrix formation. There were reports which state that biofilms acquire resistances to inhibitors under nutrient limited or depleted conditions in contrast to their susceptibility conditions. ${ }^{17}$ Sesbania grandiflora leaves extract shown to have antibiofilm efficacy under both nutrient repleted and nutrient depleted conditions, which indicate the presence of bioactive agent in the leaf extract.

Carbohydrate and proteins were considered as a main constituent of EPS in pure culture..$^{18}$ In this study, the ratio of carbohydrate and protein of the pure culture was comparatively less after treatment with Sesbania grandiflora leaves extract. UV-Vis spectroscopy analysis of control and treated EPS revealed major absorption peak at $270 \mathrm{~nm}$, which revealed that the intensity of the peak is directly proportional to the concentration of the EPS. This was similar to surface Plasmon vibration with the previous work. ${ }^{9}$ FTIR results represented that the active biomolecules present in the leaves of Sesbania grandiflora was responsible to inhibit the biofilm formation. The broad stretching of $3462 \mathrm{~cm}^{-1}$ indicates the presence of hydroxyl group. ${ }^{19}$ The band at $2942 \mathrm{~cm}-1$ was due to the presence $\mathrm{C}-\mathrm{H}$ functional groups, which revealed the presence of sugar. Another peak at $1659 \mathrm{~cm}^{-1}$ could attributed to the C-H stretching of mannose or galactose. The absorption peak at $1075 \mathrm{~cm}^{-1}$ may be attributed to O-acetyl ester linkage bond ${ }^{11}$ DLS showed that the decrease in volume number indicate the degradation of the protein molecule in EPS, and in-turn revealed the decreased stability than the control.

\section{Conclusion}

In the present study Sesbania grandiflora aqueous leaf extract inhibited the extracellular polymorphic substances formation. The EPS produced by the bacterium Staphylococcus aureus comprises carboxyl, carbonyl groups and aromatic amines. EPS degrading bioactive compounds of herbal plants play pivotal role in controlling biofilm formation in medicine field. In this study, EPS modulatory effect of Sesbania grandiflora aqueous extract was evaluated against Staphylococcus aureus and found effective. Sesbania grandiflora aqueous extract reduced components protein and 
carbohydrate formation which, a major part in biofilm synthesis Together, this study highlights the EPS modulatory potentials of Sesbania grandiflora, total modification occurred on EPS components of bacteria and stability of EPS for the first time which could be of interest to Control microbial population in field of medicine to render treatment for the microbial infection in natural way.

\section{Conflicts of interest}

The authors declare that they have no conflict of interest.

\section{Acknowledgements}

The authors gratefully acknowledge K. Sathish Kumar, N. Supraja, Department of Biotechnology, Thiruvalluvar University, Vellore and D. Sathya prabhu, Research scholar, VIT for supporting this research.

\section{References}

1. Balasubramanian S, Yan S, Tyagi RD, et al. Extracellular polymeric substances (EPS) producing bacterial strains of municipal wastewater sludge: Isolation, molecular identification, EPS characterization and performance for sludge settling and dewatering. Water research. 2010;44(7):2253-2266.

2. Novak J, Muller C, Murthy S. Floc structure and the role of cations. Water science and technology. 2001;44(10):209-213.

3. Flemming HC, Wingender J. The biofilm matrix. Nature Reviews Microbiology. 2010;8:623-633.

4. Chanda S, Kaneria M. Indian nutraceutical plant leaves as a potential source of natural antimicrobial agents Science against microbial pathogens: communicating current research and technological advances. 2011;2:1251-1259.

5. Sedigheh B, Bazzaz F, Khajehkaramadin M. In vitro antibacterial activity of rheum ribes extract obtained from various plant parts against clinical isolates of gram-negative pathogens. IJPR. 2005;4(2):87-91.

6. Ponnanikajamideen M, Nagalingam M, Vanaja M, et al. Anticancer activity of different solvent extracts of Sesbania grandiflora against neuroblastima (IMR-32) and colon (HT-29) cell lines. Europ J Biomed Pharm sci. 2010;2(3):509-517.
7. Bauer A, Kirby W, Sherris JC, et al. Antibiotic susceptibility testing by a standardized single disk method. Am J Clin Pathol. 1966;45(4):493-496.

8. Singh RP, Shukla MK, Mishra A, et al. Isolation and characterization of exopolysaccharides from seaweed associated bacteria Bacillus licheniformis. Carbohydrate polymers. 2011;84:1019-1026.

9. Bradford MM. A rapid and sensitive method for the quantitation of microgram quantities of protein utilizing the principle of protein-dye binding. Anal Biochem. 1976;72:248-254.

10. Kavita K, Singh VK, Mishra A, et al. Characterisation and anti-biofilm activity of extracellular polymeric substances from Oceanobacillus iheyensis. Carbohydrate polymers. 2014;101:29-35.

11. Lowry OH, Rosebrough NJ, Farr AL, et al. Protein measurement with the Folin phenol reagent. J biol Chem. 1951;193(1):265-275.

12. Hedge J, Hofreiter B, Whistler R, et al. Carbohydrate chemistry. Academic Press, USA, 1962;pp.266.

13. Bramhachari PV, Dubey SK. Isolation and characterization of exopolysaccharide produced by vibrio harveyi strain VB 23. Lett Apply Microbiol. 2006;43(5):571-577.

14. Arun A, Karthikeyan P, Sagadevan P, et al. Phytochemical screening of Sesbania grandiflora (Linn). Int J Biosci Nanosci. 2014;1:33-36.

15. Maeda T, Garcia-Contreras R, Pu M, et al. Quorum quenching quandary: resistance to antivirulence compounds. The ISME journal. 2012;6:493-501.

16. Sutherland IW. Microbial exopolysaccharides-structural subtleties and their consequences. Pure and Applied Chemistry. 1977;69:1911-1918.

17. Nwodo U, Okoh A. Characterization and flocculation properties of biopolymeric flocculant (Glycosaminoglycan) produced by Cellulomonas sp. Okoh. J Appl Microbiol. 2013;114(5):1325-1337.

18. Iyer A, Mody K, Jha B. Characterization of an exopolysaccharide produced by a marine Enterobacter cloacae. Indian J Exp Biol. 2005;43:467-471.

19. Freitas F, Alves VD, Carvalheira M, et al. Emulsifying behaviour and rheological properties of the extracellular polysaccharide produced by Pseudomonas oleovorans grown on glycerol by product. Carbohydrate polymer. 2009; 78:549-556. 